\title{
Delayed Presentation of Gongenital Diaphragmatic Hernia as Heart Failure
}

\section{Waiz Wasey, Neha Wasey}

From the Shadan Institute of Medical Sciences, Hyderabad - India.

\section{Abstract:}

Congenital diaphragmatic hernia $(C D H)$ is rare congenital condition that primarily presents in infants. Bochdalek hernia is the most common of them. Late presentation is unusual, and in most cases is diagnosed in adolescents or early adulthood. Morgagni hernia is the one that usually presents late in adults. The finding of $\mathrm{CDH}$ in adults is mostly incidental. We report a case of $\mathrm{CDH}$, posterolateral (Bochdalek type), with left lung hypoplasia, in a 60 year old female, who primarily presented with sudden shortness of breath.

Key words: Hernias, Diaphragmatic, Congenital, Dyspnea, Diaphragm, Abdominal Cavity.

\section{Introduction}

Congenital diaphragmatic hernia is a rare congenital defect in the diaphragmatic musculature allowing the abdominal viscera to bulge into the thoracic cavity. This condition is mostly seen in infants, with an incidence of 1:3000 live births [1]. The most common of them is Bochdalek hernia, which is a posterolateral defect. The abdominal contents usually herniate from the left side, this is mainly because the liver protects the right side of the thoracic cavity. CDH is also associated with lung hypoplasia on the side on the defect. To date less than 100 cases of Bochdalek hernia has been reported in adults [2], and many of those findings were incidental. These patients usually present with difficulty in breathing or pneumonia like symptoms or gastrointestinal symptoms and end up being diagnosed with $\mathrm{CDH}$. $\mathrm{X}$ rays and $\mathrm{CT}$ scan are routinely used to diagnose $\mathrm{CDH}$. Our case is a 60 year old female who presented with sudden onset dyspnea and low blood pressure, eventually being diagnosed as heart failure. Nonresolving of symptoms lead to the incidental finding of the hernia.

\section{Case Report}

A 60 year old female presented in emergency with sudden onset of dyspnea. There was no associated chest pain or fever. The patient had not witnessed such an episode before, though over the course of time she did feel to develop short of breath on exertions. Her current episode though, developed at rest.

The patient had a healthy medical history with no hypertension, diabetes or episodes of myocardial

Corresponding Author: Dr. Waiz Wasey

Email:waiz86@gmail.com

Received: July 25, 2014 | Accepted: July 30, 2014 | Published Online: August 10, 2014

This is an Open Access article distributed under the terms of the Creative Commons Attribution License (creativecommons.org/licenses/by/3.0)

Conflict of interest: None declared | Source of funding: Nil | DOl: http://dx.doi.org/10.17659/01.2014.0073 
infarctions. She did however have indigestion problems at times, for which she took over the counter antacids. On physical examination, jugular venous distension was noted with markedly decreased breath sounds on the left side and bilateral pedal edema. Her pulse oximetry was $88 \%$, she had low blood pressure $(80 / 60 \mathrm{mmHg})$ and was tachycardic. Initial EKG done was normal and labs revealed no increase in cardiac enzymes. A stat X-ray, demonstrated massive pleural effusions on the left side, and mild effusions on the right. 2D echo, demonstrated an ejection fraction of $30 \%$. She was put on oxygen, given furosemide and started on intravenous fluids. Considering she might require additional ventilator support and having a provisional diagnosis of heart failure, she was shifted to the ICU. In the ICU the patient was put on CPAP after no significant improvement was noted on her $A B G$ and saturations, and was started on low dose inotropes to treat her heart failure. Next day her oxygen saturation improved to $90 \%$ and her blood pressures were in normal range. Despite the subtle improvement, the patient still complained of difficulty breathing and could not maintain off oxygen. A repeat chest X-ray [Fig. 1] still showed massive pleural effusion on the left side. While performing a physical exam on the chest to attempt pleural tapping, a rubbing sound was heard in the left thoracic cavity. After a consultation with the pulmonologist, a CT scan was done before planning therapeutic pleural tapping. What was seen on the CT scan [Fig.2] was shocking, and took the whole team by surprise. The patient had a left sided diaphragmatic hernia (posterolateral type) with hypoplasia of the lung. As she never had any abdominal trauma, surgeries or reasons to have developed an acquired hernia, it was of consensus declared congenital. The abdominal contents in the thoracic cavity were pressing on the heart, causing heart failure.

The patient and her family were immediately counselled regarding the condition and immediate need for surgery and was referred to a specialist centre for the corrective repair.

\section{Discussion}

Congenital diaphragmatic hernia is a birth anomaly in which the abdominal contents move into the thoracic cavity from a defective opening in the diaphragm, as a result of developmental defect. The incidence of this congenital defect is 1 in every 3000 live births [1]. There are 3 types of $\mathrm{CDH}$, namely: Bochdalek hernia - which is a posterolateral defect, Morgagni hernia - an anterior defect and hiatus hernia.

Of these, the left sided Bochdalek hernia is the most common, occurring in $85-90 \%$ of the time [3]. Though this condition is usually diagnosed early in life, a few 100 cases have been reported in adults, most of them being incidental findings.

In contrast to the presentation in infants, which is respiratory distress, most adults present with chronic dyspnoea, chest discomfort, abdominal pain and gastrointestinal irritation [4]. Our patient presented

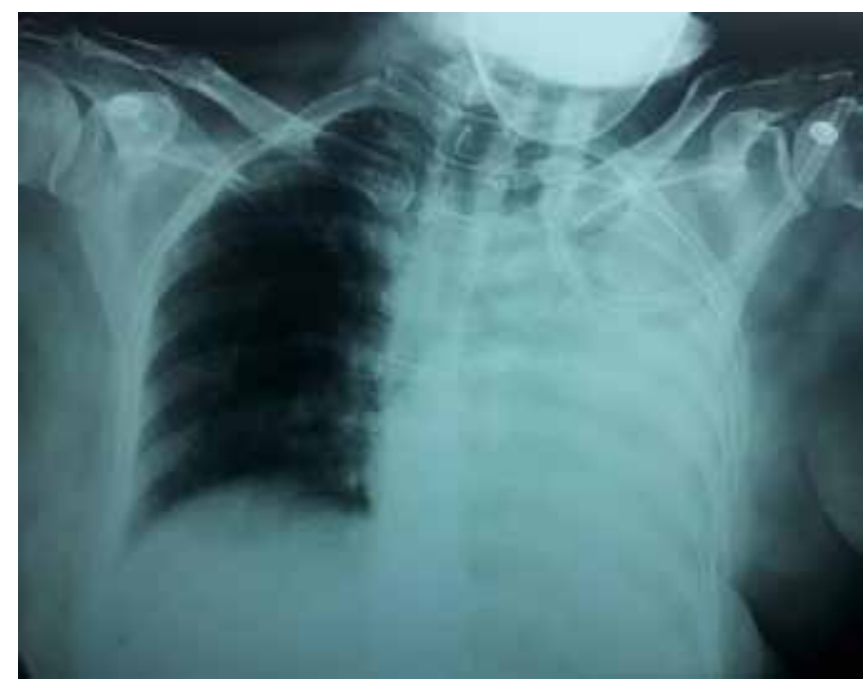

Fig.1: X-ray showing massive pleural effusion like picture in the left thoracic cavity. 

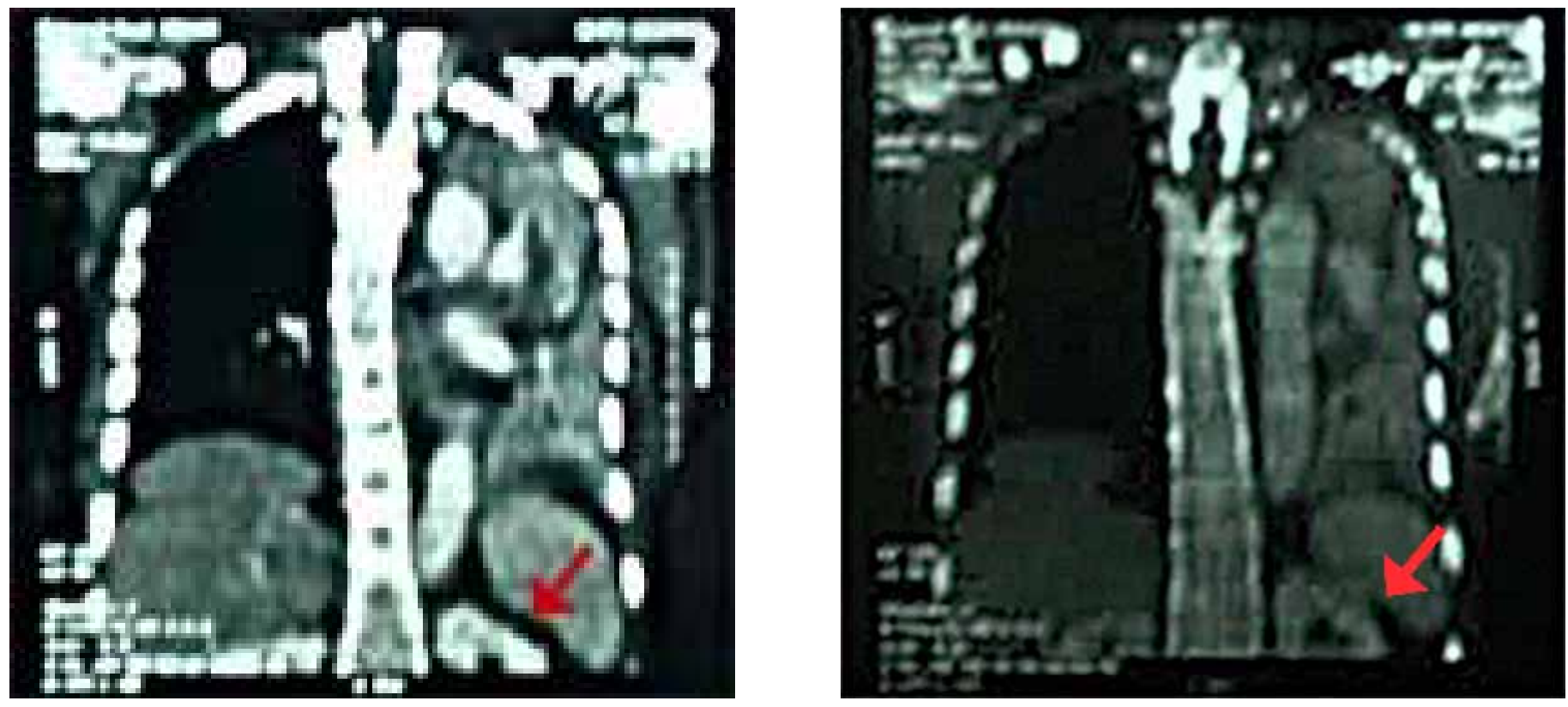

Fig.2a,2b: Longitudinal thoraco-abdominal CT showed the left thoracic cavity was completely filled with abdominal organs reaching to the apex of the left thoracic cavity.

with shortness of breath secondary to heart failure and did show some history of indigestion and postprandial fullness. On examination these patients have a scaphoid abdomen, signs of respiratory distress (cyanosis, chest retractions and grunting), decreased breath sounds, shifting of cardiac sounds and abnormal bowel sounds in the thoracic cavity [5]. Our patient however did not have these classic presentations, except for decreased breath sounds and an abnormal sound in the left thoracic cavity. The cardiac sounds were dull, but were not perceived to be shifted.

$\mathrm{CDH}$ is diagnosed using imaging techniques like chest X-ray, CT scan or MRI. A chest X-ray would show bowel loops in the thoracic cavity with air shadows. However, this was not the case in our patient. The $\mathrm{X}$-ray appearance was misleading and did not help in the early diagnosis. A typical CT scan finding comprises of abuttment of fat or soft tissue contour on the upper diaphragmatic surface. [6]. Other tests that may help as adjuvants to the diagnosis include $A B G$ studies, serum lactate, electrolytes, renal ultrasound and cardiac echo [7]. These extra imaging tests may be done to rule out other medical syndromes, as at least $10 \%$ of $\mathrm{CDH}$ s have been documented to be associated with syndromes [8] such as Cornelia de Lange, Fryns syndrome [9], Turner syndrome and Pallister-Killian syndrome.

The principle management of Bochdalek hernia is reducing the abdominal contents and repairing the defect. This can be done either through a thoracotomy or a laparatomy. The use of either one is solely dependent on the surgeon. The factors that lead to the decision depend on the type of hernia, amount of abdominal content and skill of the surgeon. Most surgeons advocate a transthoracic approach for left sided hernias [10]. Thoracotomy repair is used often for large defects. As was in our case, the outcome of the patients depend of the size, duration, organs involved, lung condition and if there is any associated medical syndrome [11]. 
Better prognosis is seen with early diagnosis and treatment.

\section{Conclusion}

Congenital diaphragmatic hernias are rare developmental defects that are seen in neonates and infants. Very few cases have been reported in adults, and we report this rare case of left sided Bochdalek hernia in an adult female who presented with dyspnoea. Most of the time this disorder is either misdiagnosed or late diagnosed in adults, which leads to more morbidity and mortality.

\section{References}

1. Langham MR, Kays DW, Ledbetter DJ, Frentzen $B$, Sanford LL, Richards DS. Congenital diaphragmatic Hernia: Epidemiology and outcome. Clin Perinatol 1996;23:671-688.

2. Rout S, Foo FJ, Hayden JD, Guthrie A, Smith AM. Right-sided Bochdalek hernia obstructing in an adult: case report and review of the literature. Hernia 2007;1 1:359-362.

3. Clark RH, Hardin WD Jr, Hirschl RB, Jaksic $T$, Lally KP, Langham MR Jr, Wilson JM. Current surgical management of congenital diaphragmatic hernia: a report from the Congenital Diaphragmatic Hernia Study Group. J Pediatr Surg 1998;33:1004-1009.
4. Nitecki S, Bar-Maor JA. Late presentation of Bochdalek hernia: our experience and review of the literature. Isr J Med Sci 1992;28:711714.

5. Keijzer R, Puri P. Congenital diaphragmatic hernia. Semin Pediatr Surg. 2010;19:180-185.

6. Wilbur AC, Gorodetsky A, Hibbeln JF. Imaging findings of adult $B$ ochdalek hernias. Clin Imaging 1994;18:224-229.

7. Haugen SE, Linker D, Eik-Nes S, Kufaas T, Vik T, Eggen BM, Brubakk AM. Congenital diaphragmatic hernia: determination of the optimal time for operation by echocardiographic monitoring of the pulmonary arterial pressure. J Pediatr Surg 1991;26:560-562.

8. Zaiss I, Kehl S, Link K, Neff W, Schaible T, Sutterlin M, Siemer J. Associated Malformations in Congenital Diaphragmatic Hernia. Am J Perinatol 2010;28:211-218.

9. McPherson EW, Ketterer DM, Salsburey DJ. Pallister-Killian and Fryns syndromes: nosology. Am J Med Genet 1993;47:241-245.

10. Yamaguchi $M$, Kuwano $H$, Hashizume $M$, Sugio K, Sugimachi K, Hyoudou Y. Thoracoscopic treatment of Bochdalek hernia in the adult: report of a case. Ann Thorac Cardiovasc Surg 2002;8:106-108.

11. Sweed Y, Puri P. Congenital diaphragmatic hernia: influence of associated malformations on survival. Arch Dis Child. 1993;69:68-70. 